\title{
Achieving Income Justice in Professional Sports: Limitation, Taxation, or Donation
}

Authors' contribution:

A) conception and design of the study

B) acquisition of data

C) analysis and interpretation of data

D) manuscript preparation

E) obtaining funding

\section{Gottfried Schweiger}

University of Salzburg, Austria

\section{ABSTRACT}

This paper is based on the assumption that the high incomes of some professional sports athletes, such as players in professional leagues in the United States and Europe, pose an ethical problem of social justice. I deal with the questions of what should follow from this evaluation and in which ways those incomes should be regulated. I discuss three different options: a) the idea that the incomes of professional athletes should be limited, b) the idea that they should be vastly taxed by the state, and c) the idea that there is a moral obligation for the athletes to spend portions of their incomes on good causes. I will conclude that in today's circumstances there are good reasons to advocate both option one (limitation) and option two (taxation), but that priority should be given to taxation.

KEYWORDS $\quad$ social justice, professional sports, income justice, philosophy of sport

\section{Introduction}

There are good reasons to conclude that the high incomes earned by professional sports athletes in leagues such as the National Hockey League and Major League Baseball in the United States, or the Bundesliga in Germany, are socially unjust and that they cannot be justified from an ethical point of view (Schweiger, 2012). But such a conclusion is only the starting point for a variety of more, and sometimes even more complicated, questions. In particular, to design the change of practice, whether it be on the individual, the organizational or the political level, is difficult and intertwined with conflicting interests, limited possibilities, and other contingencies that are often alien to the realm of "pure" philosophical theory. Nonetheless, any ethical theory, and any theory of social justice, would be pointless if it were not able to influence practice and change.

In this paper I ask what should follow from an evaluation that the high earnings of professional sports athletes are socially unjust. I see three possible ways to achieve social justice to professional sports with regard to these high incomes. First, there is the possibility that one could argue for a limitation or a cap on the incomes of athletes. For various other reasons, such limits are already imposed in several leagues, which operate with a salary cap. Second, justice could be achieved by taxing the incomes of sports athletes on a much higher level than today, which would lower their actual income to a socially just height. Different versions of this option are used in various states, although not explicitly for sports athletes but rather for all high-income earners. Third, one could refrain from any actions by a governing body or the state and leave the matter to the athletes themselves, arguing that there is no justification for forcing income justice. 
However, as the high incomes of professional sports athletes are socially unjust, it is their responsibility to donate or otherwise use their income for the common good. While options one and two ask for regulation by the state or any other institution, the third option leaves it to the individual and is therefore familiar to virtue ethics.

In a certain sense achieving income justice in professional sports also implies restoring income justice. It is a development of the last decades that the incomes of professional athletes and especially of the top earners have skyrocketed, while the "normal" population has seen a much smaller increase. In the United States - but not only there - the social and economic distance between professional athletes and the "normal" population has grown. For example, in Major League Baseball (MLB) the median income of a player in 1990 was only nine times as high as the median income of a full-time worker in the United States, in 2010 it was nearly thirty times as high. Adjusted for inflation the median salaries in the MLB tripled between 1990 and 2010 and the median salaries of the top 25 earners more than quintupled (Figure 1), while the median income of full-time workers only increased about 20 percent in the same period. Similar developments took place in all other big leagues, including the National Hockey League.

In the following sections I will first outline the scope of the problem and present briefly an argument

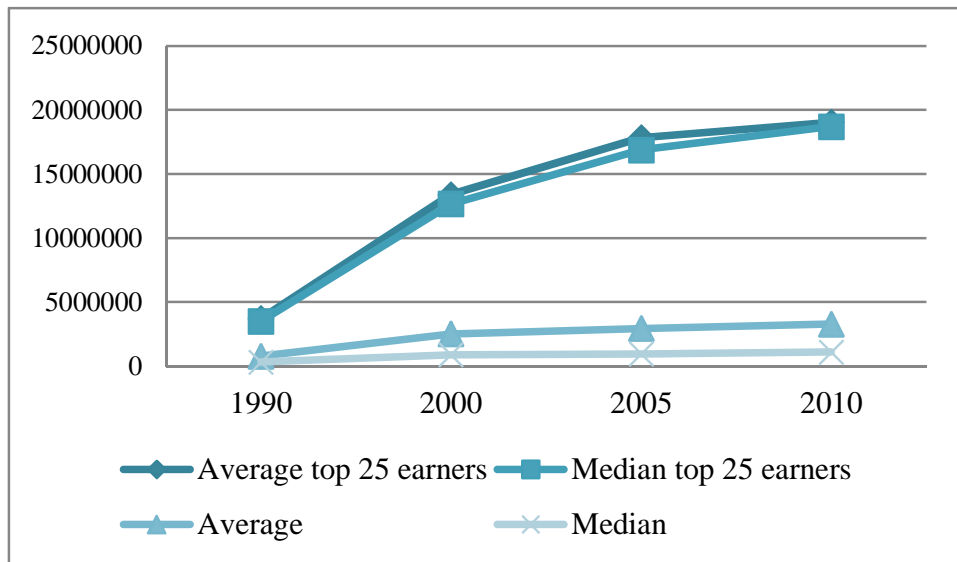

Figure 1. Average and median salaries (\$) in Major League Baseball Source: USA Today Salary Database. why the high incomes of professional sports athletes are socially unjust. This is not to be understood as a fully developed and sufficient theory but rather as indicative reasons, because the main focus of my paper lies elsewhere. In the next three sections I will then put forward arguments for the options of limitation, taxation, and donation. I will show that choosing the right option depends on the societal circumstances in which social justice has to be reached. The case for taxation is if and when there are other justified needs for redistributive measures. The case for a limi-

tation of income is if and when the distributing market is distorted and the incomes are unmerited in relation to other members of society. Finally, the option of donation is favored by many people who are, in general, skeptical of state intervention - for different reasons - and want to leave the doing of good and the establishment of social justice to the individual. In this case, there might be an ethical duty, but no duty of social justice, to do good with the incomes and to use them for the common good or humanitarian help. I will conclude that in today's circumstances there are good reasons to advocate both option one (limitation) and option two (taxation), but that priority should be given to taxation. Although my aim is general and can be applied to many different circumstances of professional sports, and maybe also other high-income earners, I will use data from the National Hockey League to exemplify my arguments. My perspective in this paper is a philosophical one, so it is not only possible but likely that other disciplines such as economics might reach different conclusions.

\section{Social justice and income: the case of the National Hockey League}

The National Hockey League (NHL) is considered the smallest of the big four professional leagues the others are Major League Baseball, the National Football League and the National Basketball Association - in the United States. It currently consists of 30 teams of which 7 are located in Canada: Montreal, Toronto, Vancouver, Calgary, Edmonton, Ottawa, and Winnipeg. The NHL implemented a salary cap through a new collective bargaining agreement (CBA), beginning with the 2005/2006 season, after a lockout that led to the cancellation of the entire 2004/2005 season. A new CBA is currently being negotiated, and it is unclear how 
things will unfold and what changes will be made to the CBA. One critical question in the current negotiations is the share of revenue between owners and players, and this certainly will affect the income structure. Overall, the NHL has flourished since the lockout and so have the salaries of the players. Overall revenues increased from $\$ 2$ billion to $\$ 3.2$ billion in 2011/2012. The salary cap went up from $\$ 39$ million to $\$ 64.3$ million (expected to be more than $\$ 70$ million in 2012/2013), and the minimum floor from $\$ 21.5$ million to $\$ 48.3$ million (NHL.com, 2011). The minimum salary rose from $\$ 450,000$ to $\$ 525,000$ in 2011/2012, which is a small increase compared to the highest allowed salary, which, on the other hand, has nearly doubled. It is set at $20 \%$ of a club's upper cap limit, meaning that it increased from $\$ 7.8$ million in $2005 / 2006$ to $\$ 12.86$ million in $2011 / 12$. The average salary of an NHL player is now - in $2011-\$ 2.4$ million, and the highest-paid players (top 25 earners) get more than $\$ 7$ million and up to $\$ 12$ million (USA TODAY, 2012a; USA TODAY, 2012b). The median salary in 2011 was less than the average - which indicates an unequal distribution - at $\$ 1.5$ million $^{1}$. The Gini index - a statistical measure for inequality - is 44.55 and the Robin Hood index 34.62, which is much lower than, for example, Major League Baseball in 2012, which has a Gini index of 62.23 and a Robin Hood index of $49.17^{2}$.

Another interesting development is that more and more star players receive very long contracts in order - from the perspective of the clubs - to circumvent the salary cap restrictions. The cap hit of an individual contract is - to put it simply - calculated by dividing the overall pay by the contract length, so that a contract of 10 years paying a total of $\$ 50$ million has an annual cap hit of $\$ 5$ million, while a contract of five years paying the same amount has a cap hit of $\$ 10$ million, regardless of how much money is paid in a specific year. So, the cap hit of front-loaded contracts paying $\$ 10$ million in the first five years can be reduced by adding five years in which only $\$ 1$ million is paid. Such contracts are especially favorable in times in which it is almost certain that the salary cap will increase and therefore the relative cap hit of these contracts decreases further over the years. Another option - which is officially not allowed but almost certain to be used in some cases - is that the cap hit of a contract is cleared if the player retires, whether the contract has ended or not. As players get most of the money in the first years of the contracts they do not lose much, but for the clubs it can be a huge relief not to have a high cap hit for contracts of older players beyond their prime. The structure of the latest 'retirement contracts' of star players reflects this opportunity for players to increase their income and for the clubs to decrease salary cap restrictions. For example, the contracts of Ryan Suter and Zach Parise, which they signed with the Minnesota Wilds, look like this (LeBrun, 2012): Years 1 and 2: $\$ 2$ million base salary $+\$ 10$ million signing bonus (=\$12 million); Year 3: $\$ 6$ million base + $\$ 5$ million signing bonus (=\$11 million); Years 4-8: $\$ 9$ million base; Year 9: $\$ 8$ million base; Year 10: $\$ 6$ million base; Year 11: \$2 million base; Years 12-13: \$1 million base.

These developments of player salaries in the NHL, especially those of high earners, are in stark contrast to the development of the incomes of the overall population of the US. Not only have they not increased, but rather they have decreased during the last couple of years due to the economic crisis. In 2010, the median income of full-time workingmen in the US was $\$ 47,715$; for women, the median was $\$ 36,931$ (DeNavas-Walt, Proctor \& Smith, 2011). The median household income was $\$ 49,445$, which represents a decrease of $2.3 \%$ from the previous year, 2009. In the years since the onset of the financial crisis in 2007, the median household income has declined by $6.4 \%$ in total. This means that the median salary of an NHL player is around 31 times as much as the median income of a full-time worker, and 30 times as much as the median US household income. The income of the 25 top earners with more than $\$ 7$ million is at least 146 times as much as the median income. The NHL minimum salary, $\$ 525,000$, is approximately 11 times as much as the median income of a full-time male worker. A single person or family living in poverty in the United States has only a fraction of what the average NHL player earns.

\footnotetext{
${ }^{1}$ The median is the numerical value separating the higher half of a population from the lower half. It is a more robust measure for unevenly distributed data such as salaries and is therefore used by most income and poverty statistics.

${ }^{2}$ Calculations based on the salary database of USATODAY.com.
} 
In this same period, unemployment and poverty rates have skyrocketed, with 46.2 million people $15.1 \%$ of the US population - now living in poverty, the highest such number since the US began tracking poverty rates in 1959 . There are many different poverty lines depending on family size and age, but I want to present here just two numbers: the poverty threshold for a single person under 65 was $\$ 11,344$ and for a family with two children $\$ 22,190$. People living below that line are in poverty, which means that they are often also affected by many different forms of hardships and restrictions that are closely linked to being poor, such as a higher risk of being (chronically) ill; social, psychological and physical stress; social exclusion; and shame. It is a strong indicator for social injustice if millions of people are suffering from poverty while a small majority such a NHL players can live in clover. To sum up: while NHL players are getting more and more - as do other pro athletes in the NFL, the NBA, or MLB - millions of people in the United States are suffering from unemployment and poverty.

As this paper is not mainly interested in all aspects of the complex issue of social justice in professional sport but rather uses a certain assumption about it as its starting point, I just want to present two indicative reasons why the relation between NHL player salaries and the income of the overall population in the United States poses an ethical problem and should be deemed as unjust. Following the work of David Miller, I understand social justice as the balance of three principles: need, equality, and desert. A social context is socially just if its members are able to satisfy their legitimate needs, if they share a set of equal rights and duties as citizens, and if all other benefits and burdens are distributed according to desert (Miller, 1999). If I assume here that at least some incomes in professional sports are socially unjust, it means that they violate this model of social justice. This can be the case if they are not deserved, if they violate the legitimate needs of others, or if they undermine the social equality implied by citizenship. Other theories of social justice might reach different conclusions and even support a highly unequal distribution of incomes between athletes and other workers, such as liberal or libertarian theories (Olsaretti, 2004).

The first argument against these salaries is that the grounds on which NHL players receive them are to be doubted. This means that although it is undoubtable that these players are excellent, hard-working athletes, that they generate profit for most of the franchises and owners and that they entertain and enrich the lives of many millions of hockey fans, there are no good ethical reasons that could justify the height of their pay. The argument that the NHL salaries are regulated by the market - and in the end by owners, who are willing to pay that much - is not sufficient in this respect, simply because the market is not an ethics machine that produces just results but is rather distorted (Granovetter, 2005). There have to be other reasons to justify the incomes; it is doubtful that such reasons could be brought forward. Instead, there are arguments that NHL players do not deserve that much more money than other workers because the value of their work is not much higher and because their contributions are of minor social value. Playing hockey in the NHL is entertaining but nothing more. One could further argue that the players' salaries are based on brute luck because players are not responsible for their natural talents. According to such arguments players deserve nothing for playing hockey.

The second line of argument proposes that there are external but nonetheless important reasons to criticize the current height of NHL player salaries. It is not necessary to ask whether these incomes are merited or not, because it can be shown that they are in conflict with other ethical values. Such could be the general idea of an equal society, in which differences should be kept within certain limits and in which poverty should not exist (Barry, 2005). Another reason could be the global picture of severe worldwide poverty, hunger, child mortality, and the consequent moral duties of the better-off (Mack et al., 2009). A third one is the relation between income distribution and health, and that it is better for everyone if income is distributed more equally (Wilkinson \& Pickett, 2009).

Both lines of argument claim that what is in question is not whether NHL players should get a decent salary, and not even whether this should exceed that of the average employee, but rather that there are ethical limits to this difference and inequality. How to set this limit is another and even more complicated question, which I cannot further pursue in this paper. Instead, I want now to discuss three possible answers to the question of what should follow from the conclusion that the height of NHL player salaries is socially unjust. 


\section{The limitation of income}

The first possible solution is to limit players' salaries. As previously mentioned, the exact limit similar to poverty lines, one could talk about an 'unethical richness line' - is hard to determine and to some extent always bound to arbitrariness, but the idea is nonetheless compelling. A bottom limit is employed in many countries as a minimum income for full-time employment, or in different branches set by collective agreements. As already stated, the NHL itself uses both a bottom and an upper limit, in the form of a minimum income which is guaranteed for every player in the NHL and a maximum income which is relative to the salary cap. Obviously, they have not been implemented or justified by ethical reasons but rather economic ones and are the result of a bargaining agreement reached after a long work struggle which cost hundreds of millions of dollars. In general, there are good ethical reasons to think of a minimum salary as a salary which allows one to live a decent life free of poverty and humiliation and which allows one's justified needs to be satisfied (Figart, 2004). Minimum incomes are most likely to be justified by arguments of sufficiency and desert and that living beneath the threshold is morally harmful. The question of an upper limit is a different one because there is no harm for those who are overpaid and most often there is also no direct connection to the harm of others. Justifications of a minimum income can often go a more direct route and show that there is serious harm if someone is living below that level or that it reflects the lowest level of merit one deserves for doing one's work.

The main reason for an upper limit from an ethical point of view, which I want to put forward and discuss here, is to think of high incomes as being undeserved. A limit therefore corrects unjust market results and ensures that no one gets more than he (or she) deserves. Such an argument does not aim to show that others are harmed by high incomes but that they are in themselves unjust and unethical. In the example case of the NHL discussed here, this implies that these incomes are not merited and that they should be limited.

In general, desert can be understood as a four-part relation: $X$ deserves ,a” from $Y$ in virtue of „,b”. A NHL player $X$ deserves an income of ,a” from his club $Y$ in virtue of b. So a critique has to show that ,a” does not adequately reflect „b”. „, b" can be either the individual athletic performance of the player - e.g. goals scored, assists, shutouts - or the performance of the whole team to which he has contributed - e.g. wins, qualification for the playoffs, or winning the Stanley Cup - but it can also be some other good that is only indirectly linked to the athletic performance - e.g. the revenue of the club, merchandising sales or attendance. The use of different desert bases will lead to different assumptions about the ethical status of the earned income. In the case here, I want to criticize the desert base "playing hockey in the NHL" without any further reflection on differences in athletic performance or the economic goods produced by it.

One argument can now, for example, refer to the relation of the incomes of NHL players to the incomes of other workers, and especially those occupations which are of high social value, such as education or health care, but which are paid much less. Is it fair that a schoolteacher gets much less, that someone who works hard to save lives, to help the sick and the elderly gets paid only a fraction of those superstars? "Playing hockey in the NHL" does not justify that much higher of an income. The basic idea behind this argument is to say that desert can justify differences in incomes but that social justice implies a robust understanding of social and economic equality that demands to keep these differences in limits. A socially just society, according to the principles I have outlined before, should recognize and reward efforts, talents and performances - as "playing hockey in the NHL" - but it should also secure that different desert bases are taken into account. Social and economic value should be equally important.

Furthermore, there are arguments that playing hockey is in itself such a meaningful activity, accompanied by respect and social status, that these benefits should lead to a decrease in income, while doing meaningless or less enjoyable work should be compensated by higher earnings (Sayer, 2009). In general, a limitation of high incomes brings forward the idea of social equality for all citizens without the need to deny the idea of difference based on desert.

There are, of course, serious objections to such an understanding of desert. In general, desert does only play a minor role in many theories of social justice and some of which would argue that "playing hockey in 
the NHL" is the result of brute luck, that no player is responsible for his natural talents or the right birthplace and that NHL players deserve nothing at all for being lucky (Olsaretti, 2004). On the other hand, there are arguments that any interference with the market is unjust and that the market is best suited to determine what workers and hockey players deserve. Both objections should be taken seriously, and I cannot hope to refute them here. Nonetheless, I want to make two points. First, desert plays an important role in everyday moral reasoning and should not be dismissed all too easily, particularly in professional sports and in the sphere of work people want to be recognized for their individual efforts and performances. Axel Honneth's theory of recognition convincingly argues that desert has such an intrinsic and moral value, which is important for social equality (Honneth, 2003). Second, it can be argued against the liberal or market-oriented justification of income that the market is in fact distorted and favors certain activities. Also, professional hockey and the salaries one can earn for it are distorted in many ways. The public interferes and subsidizes stadium and infrastructure, sugar daddies interfere and push franchises, the natural lottery interferes and gives some players better talents, and teams in bigger markets have advantages that have nothing to do with their performance on the ice. Simply put, there is no equality of opportunity and no ideal market that would determine the salaries in the NHL.

In Table 1, I present four hypothetical models of a limitation of NHL salaries towards social justice. Such a limitation could be a maximum income similar to the one that can be found right now in the NHL. In ethical terms, this form of limitation would rest on the assumption that there is an upper limit to what anyone can deserve for playing hockey. This could either be a single number, like say $\$ 1$ million, or a number relative to other factors. The NHL currently allows $20 \%$ of the salary cap as the maximum income. But it would also be possible to set the limit at 10 times as much as the median income of the overall population in the United States, which would be around $\$ 500,000$. Today the ratio of the median income of NHL players to that of full-time workingmen is 1 to 31.25 . To lower this ratio would send the message that NHL players are special and deserve high incomes but that they are not that much more special than anybody else. Playing hockey is important but its importance has some limits. It would strengthen the sense of equality. Another possible form of limitation would be more specific with regard to different forms of playing hockey. For example, there could be different upper limits for different positions or different upper limits depending on the actual performance of a player. A more sophisticated version of such performance-sensitive limits would be to pay all players solely based on their performance. This could be done by determining the incomes of all players after the season ended based on certain statistical factors or reviews. There would then be no more need for contract negotiations and everyone would be paid what he deserves. There are serious concerns that would come with such a solution, as this would significantly reduce the power of players towards the owners, increase the pressure on players, and leave them more or less insecure and vulnerable in the case of injury. But in general, the idea of limiting the incomes of NHL players would bring forward one core idea of social justice: inequalities should be limited and the principle of desert sometimes demands to interfere.

Table 1. Possible models of a limitation

\begin{tabular}{ll}
\hline Maximum income & Examples \\
\hline set as a percentage of the salary cap & $\begin{array}{l}\$ 12.86 \text { million (current CBA) } \\
\$ 1 \text { million }\end{array}$ \\
set at a fixed number & $\begin{array}{l}\$ 477,150 \text { (ten times as much as the average annual } \\
\text { set in relation to the median income of the overall } \\
\text { population }\end{array}$ \\
set in relation to the minimum income of the NHL & $\begin{array}{l}\$ 5.25 \text { million (ten times as much as the minimum income } \\
\text { under the current CBA) }\end{array}$ \\
\hline
\end{tabular}

Source: own study.

\section{Progressive taxation and the needs of others}

The second idea is that of taxation. This says that it is not necessary or even just to directly limit the salaries of NHL players, but that it is demanded that they should be taxed on a much higher basis. This is what is in general applied by many states across the world that have progressive tax systems. Higher-income earners not only pay more taxes but higher tax rates. There are several arguments for progressive taxation, 
and I do not want to dive into this discussion here in detail but only refer to two arguments that would support the claim that the incomes of professional sports athletes such as those of NHL players should be rigorously taxed.

In general, it is widely acknowledged that states need taxes to fulfill their various tasks and that at least some of these tasks are ethically justified and demanded by social justice. The provision of a whole range of public goods, security, and stability can best be served by the state or public institutions. So, the general claim for taxation is well based, but different forms and levels of taxation are highly disputed. My main argument here refers to the need of others to justify a rigorous taxation of the incomes of professional sports athletes. This argument can, but does not have to, rely on the assumption that the height of incomes is in general ethically dubious or unmerited. In contrast, I will assume that NHL players do in fact deserve what they earn and that the distribution of their income is undistorted. On the background of these assumptions, I still think there can be good reasons to opt for taxation and, furthermore, come to the conclusion that such a taxation, which significantly lowers the incomes of NHL players, would be socially just.

As already stated, merit is not the only principle of justice and there can be other duties of justice or ethics that might interfere with it. Again, Miller's tripartite model of social justice can be used as a useful starting point here. As said, he claims that social justice depends on the connection between the principles of need, desert and equality, and that they are of equal importance. Incomes, the benefit of which I am concerned with in this paper, should in general be distributed according to desert, but if and when there are legitimate claims for need and equality then the desert principle has to step back and give them priority. This weighting rests on normative and empirical claims and follows in the steps of Honneth (Honneth, 2003).

First, the principle of need is basic because it is a precondition for the other two. Without a decent living standard - or as is the case in extreme situations where the possibility of leading any form of human life is in danger such as absolute poverty - it is not possible to execute the other two principles. Rights and duties of citizenship - the content of equality - rest upon the satisfaction of basic needs. There can be no social equality if some are living in poverty while others live in clover. No one can enjoy any right that is supposedly protected by society if he or she lacks the essentials for a reasonably healthy and active life. Deficiencies in the means of subsistence can be just as fatal, incapacitating, or painful as violations of physical security. The resulting damage or death can at least as decisively prevent the enjoyment of any right as can the effects of security violations (Shue, 1996).

Second, as the principle of need precedes the principle of equality, they both have priority over the principle of desert. A distribution according to effort and talents in a market society can only be just if no one has to work under exploitative conditions to secure a decent living for himself or herself and his or her family, and it can also only be just if equal rights and duties are secured for all participants in the market. The principle of desert can also be violated if people are vulnerable and have to agree to work for less than they deserve. Such forms of exploitation cannot be justified by the principle of desert even if people are free on paper to decline to work under such circumstances. A market can only function properly as long as it is bound by certain rules and does not allow a few agents to bend the rules as they like.

So there are reasons to interfere with market outcomes - which the incomes in the NHL and those of professional athletes in general are - if there are legitimate needs or claims of equality. I think that this is one of the main ideas behind any justification of taxation and redistribution through the welfare state that collects those taxes. This is just a raw model but it is solid enough to substantiate my claim that there are good reasons for taxation even in such cases in which the distribution of income in a certain market such as the NHL is evaluated as merited. The principle of desert is overridden if parts of these incomes are needed for a higher good and to achieve social justice in other areas of society. Such cases can be the prevalence of poverty and social exclusion - some would like to restrict this to domestic poverty, other theorists take a global perspective here - or the need to maintain public goods such as education and health care. Also, in the case of a legitimate war, which costs more than the state has at its disposal, a rigorous taxation might be justifiable. Here I want to stick to the poverty argument, because the numbers, which I have already 
presented, are quite compelling. While the NHL is flourishing and their players become millionaires and some of them are highly recognized idols, many millions of people in the United States - not to mention the global scale of this problem - are suffering from the consequences of the current economic crisis. Unemployment and poverty, homelessness and even malnutrition and hunger are prevalent, and millions are in danger of becoming "invisible". The taxation of the incomes of NHL players would certainly not solve these problems, but they could be part of a solution that puts the needs of those suffering over the merits of those who "land soft" anyway. The taxation model does not have to opt for taxing NHL players, other professional athletes, or any high-income earner to the subsistence level - the principle of desert is not to be completely overruled. But, for example, taxing all incomes over $\$ 1$ million by $75 \%$ would still leave enough difference to reflect the "achievement principle" of desert (Hartmann \& Honneth, 2006) and could provide the state with the urgently needed funds to cut its debt, invest in the labor market, and strengthen the welfare state for those who are in need. Such considerations become even weightier if and when there are good reasons to think of these high incomes not only as socially unjust because of the legitimate needs of others but also unmerited. Then, their taxation would fulfill the duties of social justice: correct unfair market outcomes and help others.

I want to consider at least one possible objection to this argument. One can say that hockey players are certainly not responsible for the conditions of the poor in the United States and that this does not justify taking some of their money away to help the poor. As I will also consider in the next section, one can either defend a strong version of this objection that says that there is no ethical obligation of the NHL players to help these poor people at all or one could defend a weaker version which says that there is an obligation to help but no obligation of social justice that would allow the state to force this help. Furthermore, one could argue that helping the poor with tax money has negative effects on the poor themselves or for the society as a whole. The welfare state gets bigger and bigger, evermore people become dependent and the incentives to seek work and care for oneself diminish. Again I can not hope to give a fully convincing answer to this objection because this would demand a much more detailed and empirically informed discussion about the welfare state, social policy, and different models of society in general. What I want to make clear is that there is an ethical obligation to help the poor, that this obligation exists especially towards fellow citizens, and that the welfare state can fulfill this function. First, I follow Christian Neuhäuser and Julia Müller that the duty to end or alleviate poverty exists regardless of its causes because poverty is always connected to moral harm. They write

But even if it is true that some people are relatively poor due to their own fault, society still has reason to end their poverty. This is because relative poverty is not a problem of fairness but a problem of decency. A decent society does not tolerate that its members are humiliated. [...] A decent society, therefore, has to end relative poverty no matter why it exists (Neuhäuser \& Müller, 2011, pp. 170-171).

Second, to help fellow citizens is not only easier to accomplish because of a shared set of public institutions but it also enjoys priority because it is based on a shared understanding of solidarity and community. Such an understanding as a solidaristic community in which those in need are helped is the basis for social justice and for the functioning of many other important features such as democratic procedures, trust in the political structures, or economic cooperation. Third, it is in fact questionable if modern welfare states function properly and efficiently and there is much room for improvement. It is also indeed questionable if today's poverty alleviation policies are the best available and if a system that only sends money to the poor can make lasting changes. It is widely understood that effective and sustainable poverty reduction and alleviation depends on the interaction of a set of measures including welfare provision, education, and political and economic participation. Also, different agents and institutions are needed to implement these measures, some of them on the local level, some on the state and others on the federal level. The reason why they should be financed through taxation and not predominantly through private funding is that the state and its institutions can secure this funding - it is always possible that private donors opt out and 
decide to quit funding - and that welfare provision for the poor should be a legal right. Only the state can secure this right.

\section{Virtue ethics and the idea of donation}

The third option I want to discuss is that of voluntary donation, which is favored by many people who are in general skeptical of state interventions - for different reasons - and want to leave the doing of good and the establishment of social justice to individuals. They, and not public institutions, are the main targets of ethical reasoning and the agents of social justice. This can be supported by pragmatic and normative arguments. Pragmatic arguments say that states and their institutions are inefficient in many different ways, such as that they spend the money on the wrong causes, that money is wasted, or that they are corrupt or ideologically distorted. Normative arguments basically come from two backgrounds.

First, one could say that the incomes earned by NHL players are not unethical or socially unjust at all but that it would still be a good thing if the players would do some good with their money. A more robust version of such a claim could be to speak of a moral duty to give something back to the community and to help others, but that such a duty cannot and should not be enforced. Giving is a virtue, but that does not mean that there is anything unethical in earning millions of dollars for playing ice hockey. And in fact, a lot of players are active in charities, on which they spend some of their money, or have their own foundations. There is even an award, the NHL Foundation Player Award, which is awarded annually to the player "who applies the core values of (ice) hockey - commitment, perseverance and teamwork - to enrich the lives of people in his community" (NHL.com, 2012).

The second possible line of argument says that there are reasons to think of NHL player salaries as unethical or unjust but that there are no reasons to intervene, whether be it through a limitation or taxation. So here the claim is much stronger - in saying that there is an ethical problem with these incomes - but it is cautious with regard to the consequences it wants to pursue. One can think of other examples in which such a line of argument can be used, such as cheating or lying. There are some cases in which both are severely punished - such as lying in court as a witness - but there are many, many cases in which one might say that these behaviors are morally wrong but that it would be absurd or even unethical to regulate them in any other way than with "soft" sanctions. Examples of such cases are lying to a friend, cheating on your boyfriend, or being rude to others. There are good reasons why these are not regulated by the law, such as that they affect a private sphere that should not be tampered with by the state, that an unjustifiably high amount of resources would have to be invested to monitor and sanction such behaviors, or that they fall under other important rights such as the freedom of expression. A different form of this argument can be based on the idea of subsidiarity, which demands that every problem should be solved on the level where it can best be solved, and that it is wrong if a higher entity (like the state) interferes with the agenda of a lower one (like the individual) if it is not necessary.

The option of donation also depends on the context one takes into account. In a rich country, where there is no poverty, and under the assumption that the incomes are merited, there might not even be a moral duty to spend money on charity. To modify one example of Amartya Sen, one can say that in a country where everyone has at least one Cadillac but some have 20, it is not a duty of ethics, nor one of social justice, that those who have 20 spend some of their Cadillacs on those who have just one or two (Sen, 1983). But the situation is completely different if there exits another country in which people suffer from poverty, illness, and other forms of unnecessary hardship. Then those who are better off are obliged to help and to give whether they want to or not. Whether the current social reality in the United States and around the world calls for duties of ethics or for duties of social justice, and which entities (states, organizations, and individuals) bear what kind of obligations, are two of the currently debated issues within global and social ethics and philosophy. 


\section{Conclusions: ideal and non-ideal circumstances}

I have discussed three possible answers to the question of what should and could be done with the high incomes of professional sports athletes and I used the NHL as an example. Similar considerations could be applied to other leagues and sports, and maybe also to high incomes in general. All three options depend on the social circumstances in which high incomes are paid and need further empirical evidence to be fully justified. But despite these limitations I was able to show that there are at least some reasons to support all three options discussed. I now want to weigh the three options and present reasons why under the current circumstances taxation would be the right thing to do.

I want to put forward three reasons why taxation should be given priority over limitation and donation. First, it has to be considered what would happen with the money if one were to implement an upper limit. It would certainly go into the pockets of the owners and it is highly doubtful that they would "deserve" this money. Furthermore, it would leave it to the will of the owners to decide what to do with this extra money and whether they would use it in an ethical and proper way. It is safe to say that the problem of high income would only be transferred to another level, from the players to those who pay the players. So the option of a limitation that could solve the problem on the level of players would come with side effects that would then likely pose other problems of social justice. Second, one strong argument for taxation is that the money collected by taxing high incomes could be used to solve other issues of social justice by being redistributed to the poor or used for social welfare, health care, or education (Murphy \& Nagel, 2002). As long as such problems prevail, the option of taxation is preferable to that of limitation, which would leave the money in the hands of a third party, or donation, which would leave the money in the hands of the players. This is because even if the owners or players or anyone else who is financially better off uses his or her money for the good and donate it, this help is arbitrary and is always in danger of being ended at will. Private persons or foundations do not have to justify themselves in the way government institutions have to, and receiving help from a private person is different from receiving benefits from the state. The first is humanitarian charity, the second is a right. The first can be - although it does not need to be - humiliating, while the second is an expression of citizenship.

Both these arguments are only valid under certain social conditions. It could be the case that a state has enough revenue to fulfill all its duties of social justice without taxing sports athletes or high-income earners at a very high level. One can think of a state with rich natural resources or very high income through corporate taxes. This would certainly weaken the arguments for the taxation option and one would have better reasons to advocate a limitation of incomes or an appeal to the ethical conscience of the athletes. In a different reality, it could also be the case that the incomes of NHL players could be much lower, so that they would not be socially unjust or questionable at all. Also, it could be the case that the income distribution in the United States, or even globally, would be much more equal, with the highest incomes being only ten times as much as the minimum income and not a few hundred times as much. These and other contingencies, of which some are more realistic than others, would lead to different conclusions regarding the ethical evaluation of the incomes of NHL players and what should be done. But until they change, one has to reflect on the reality of today, and that would call for a much higher taxation of the unethically high incomes of professional sports athletes such as those in the NHL. This is a demand of social justice, and professional sports should not be exempted. The area of professional sports would be a good place to start, as it is full of dreams, fandom, and admiration. Those superstars could serve as role models and inspire many more. What they get rests on what the fans give, and, especially in such times of crisis, giving back and coming down to a level of "normality" should not be a charity but a duty. A duty that is best fulfilled by taxation.

\section{REFERENCES}

Barry, B. (2005). Why social justice matters. $1^{\text {st }}$ ed. Cambridge/ Malden, MA: Polity Press.

DeNavas-Walt, C., Proctor, B.D., \& Smith, J.C. (2011). Income, poverty, and health insurance coverage in the United States 2010. Current Population Reports. Washington, DC: U.S. Government Printing Office. Retrieved from 
http://www.census.gov /prod/2011pubs/p60-239.pdf

Figart, D. (Ed.). (2004). Living wage movements: Global perspectives. 1st ed. Routledge Frontiers of Political Economy. New York, NY: Routledge.

Granovetter, M. (2005). The impact of social structure on economic outcomes. The Journal of Economic Perspectives, 19(1), 33-50.

Hartmann, M., \& Honneth, A. (2006). Paradoxes of capitalism. Constellations, 13(1) (March), 41-58. DOI:10.1111 /j.1351-0487.2006.00439.x.

Honneth, A. (2003). Redistribution as recognition: A response to Nancy Fraser. In N. Fraser, \& A. Honneth (Eds.), Redistribution or recognition?: A political-philosophical exchange (pp.110-197). $1^{\text {st }}$ ed. London/New York, NY: Verso.

LeBrun, P. (2012). Parise, Suter contract breakdowns. Retrieved from http://espn.go.com/blog/nhl/post/_id/18204/ parise-suter-contract-breakdowns

Mack, E., Schramm, M., Klasen, S., \& Pogge, T. (Eds.). (2009). Absolute poverty and global justice: Empirical data, moral theories, initiatives. $1^{\text {st }}$ ed. Farnham/Burlington, VT: Ashgate.

Miller, D. (1999). Principles of social justice. $1^{\text {st }}$ ed. Cambridge, MA/London: Harvard University Press.

Murphy, L.B., \& Nagel, T. (2002). The myth of ownership: Taxes and justice. 1st ed. Oxford: Oxford University Press.

Neuhäuser, C., \& Müller, J. (2011). Relative Poverty. In P. Kaufmann, H. Kuch, C. Neuhäuser, \& E. Webster (Eds.), Humiliation, Degradation, Dehumanization: Human Dignity Violated (pp. 159-172). $1^{\text {st }}$ ed. Dordrecht/New York, NY: Springer.

NHL.com. (2011). Salary cap set for 2011-12. Retrieved from http://www.nhl.com/ice/news.htm?id=566916

NHL.com. (2012). NHL Foundation Award. Retrieved from http://www.nhl.com/ice/page.htm?id=62989

Olsaretti, S. (2004). Liberty, desert and the market: A philosophical study. $1^{\text {st }}$ ed. Cambridge: Cambridge University Press.

Sayer, A. (2009). Contributive justice and meaningful work. Res Publica, 15 (January 21), 1-16. DOI:10.1007/s11158008-9077-8.

Sen, A. (1983). Poor, Relatively Speaking. Oxford Economic Papers, 35(2), 153-169.

Schweiger, G. (2012). Income justice in professional sports leagues: The case of the Major League Baseball. Revista Portugueasa de Ciencias do Desporto, 12 (Supl.), 160-164.

Shue, H. (1996). Basic rights. Subsistence, affluence, and U.S. foreign policy. $2^{\text {nd }}$ ed. Princeton, NJ: Princeton University Press.

USATODAY (2012a). Salaries Databases: 2012 NHL salaries by team. Retrieved from http://content.usatoday.com /sportsdata/hockey/nhl/salaries/team/

USATODAY (2012b). Salaries Databases: 2012 NHL Top 25 Player Salaries. Retrieved from http://content.usatoday. com /sportsdata/hockey/nhl/salaries/player/top-25

Wilkinson, R., \& Pickett, K. (2009). The spirit level: Why equality is better for everyone. $1^{\text {st }}$ ed. London: Penguin.

AUTHOR'S ADDRESS: $\quad$ Gottfried Schweiger

University of Salzburg, Center for Ethics and Poverty Research

Moenchsberg 2a

A-5020 Salzburg

Austria

Email: gottfried.schweiger@sbg.ac.at 